\title{
Challenges in combatting Female Genital Mutilation: Narratives of Black Sub-Saharan African (BSSA) women in the English West Midlands Region, UK.
}

Authors: Mathew Nyashanu and Maureen Mguni

\section{Abstract}

It is believed that more than 120 million women have undergone female genital mutilation (FGM) and more than 2 million young girls are at risk of undergoing FGM. FGM is practiced in different parts of the world. With Globalisation and the increased movement of people across the globe, FGM is now a global problem. While ending FGM remains a priority, the approaches and strategies being employed have generated contested views across the social divide. The purpose of this study is to explore the challenges in combatting FGM as experienced by Black Sub-Saharan African (BSSA) women in Diaspora. This qualitative study utilised a phenomenological approach. Narratives were collected from 40 BSSA women from 20 sub-Saharan African countries living in the English West Midlands region. A thematic approach underpinned by the 4 phases of data analysis in the Silences Framework was used to analyse the data. The research study found that stigmatisation of survivors, utilisation of Graphic images in FGM awareness, Exclusion of practising communities' gatekeepers in FGM interventions, Conflation of religion and FGM practice and Emphasis on securing a conviction were obstacles in combatting FGM. Diaspora community-driven studies exploring FGM and contested notions in addressing it from women perspectives are scarce. This study pulls together the experiences of BSSA women and their perspectives on contested notions in combating FGM in the UK. The debate asserts the growing need to consider gender sensitive radical interventions, which involves educating perpetrators and gatekeepers among FGM practising communities

Key terms: Female Genital Mutilation; Perceptions; Communities Black sub-Sahara African Women

\section{Introduction}

Female Genital Mutilation (FGM) is a multifarious practice, interwoven within the cultural fabric of those who practice it (Toubia, 1999; Costello, 2015). FGM as a term was first coined during the InterAfrican Committee on Traditional Practices Affecting the Health and well-being of Women and 
Children (ACTPHWC) in 1990 (Burrage, 2015). It was then adopted by the World Health Organisation (WHO) in 1997 to refer to all procedures that involve partial or total removal of the external female genitalia, or other injury to the female genitalia for non-medical reasons. The WHO categorised FGM into 4 main types so as to homogenise the terms used (Kiragu, 1995) and these include:

Type 1:"Clitoridectomy - partial or total removal of the clitoris;

Type 2: Excision - partial or total removal of the clitoris and the labia minora, with or without excision of the labia majora.

Type 3: Infibulation - narrowing of the vaginal opening through the creation of a covering seal;

Type 4: Other - all other harmful procedures to the female genitalia for non-medical purposes, e.g. pricking, piercing, incising, scraping and cauterizing the genital area" (WHO, 2008).

When talking to survivors of FGM, the term FGM must not be forced upon them as different groups and communities uses different terms and expressions to describe the different practices that constitute FGM. Martinez and Phillips (2008) states that it is respectful of the women or girls' human rights to enable them to self-identify with regards to FGM.

Dustin (2010) states that all 4 types of FGM are a violation of the rights of women and girls which carry lasting physical and mental health impacts. A study conducted by Kaplan et al (2011) amongst 871 women in different parts of The Gambia sought to evaluate the magnitude of the health consequences of FGM, dependant on the type performed. The findings indicated that the most commonly practiced type of FGM was Type 1, followed by Type 2 and that the nature of health complications were dependant on the degree of mutilation. While it is not uncommon to find this hierarchical way of classifying FGM, this study takes the view that all types of FGM are a violation of the rights of women and also carry lasting mental health impacts (Dustin, 2010). FGM in this study is therefore considered to be a form of Violence against Women and Girls (VAWG) in agreement with the (2011) Council of Europe Convention on preventing and combating violence against women and domestic violence (Burrage, 2015). 
FGM is understood to take place in many countries (United Nations International Children Education Fund (UNICEF), 2013), the majority of cases being reported in Africa, the Middle East and Asia with fewer cases in South America. Due to migration, FGM has became a global pandemic, affecting all countries where potentially practising communities have chosen to settle (Wadesango, Rembe \& Chabaya, 2011). In England and Wales, there is no local authority free from FGM (Wigmore, 2015). Statistics from research conducted by City University in London show that in 2011, there were 103,000 women from communities that potentially practice FGM living in England and Wales (Macfarlane and Dorkenoo, 2015). In 2015, there were approximately 60,000 girls aged 0-14 in England and Wales whose mothers had undergone FGM (Macfarlane and Dorkenoo, 2015). According to Berg and Underland (2013), there were 5,700 newly recorded cases of FGM between 2015 and 2016, 20,000 girls are believed to be at risk of FGM each year and 137,000 girls and women are believed to be living with the consequences of FGM in the UK (Milward et al, 2016). National Health Trusts and GP practices identified 9,179 new FGM cases for the period April 2016 to March 2017 (Chisnell and Kelly, 2019). Of this figure, $95 \%$ of these women and girls had undergone FGM before they were 18 years old (Female Genital Mutilation (FGM) Enhanced Dataset, 2017). Over 100 girls were identified as having, or being treated for FGM related cases, in England in 2015/16 (Bently et al, 2016). It is estimated that approximately 200 million girls have been cut worldwide, with the majority being cut by the age of 15 (WHO, 2018). A joint WHO/UNICEF/UNFPA statement on FGM (2007) declared that "even though cultural practices may appear senseless or destructive from the standpoint of others, they have meaning and fulfil a function for those who practice them" (WHO, 2007). It is therefore important to understand the cultural and religious notions attached to the rationale for FGM in practising communities in order to effectively combat it. It is also important that conversations to combat FGM should actively include women who are primarily impacted upon by the phenomenon (Wilson, 2013).

Within literature, there are differing reasons given for the practice of FGM and these vary from country to country and at times the various regions in the same country have different reasons for the practice. 
According to Kandel (1999), FGM was historically an Ancient Egyptian practice, for the purposes of controlling women's sexuality. Kandel further states that although considered a foreign concept in modern day Britain, clitoridectomy was a practice recognised as a means of managing epilepsy and mental illness. Momoh (2003) propounds that the Romans, used a method where rings were slipped in the labia majora to prevent pregnancy amongst female slaves; for the Russian Scopsti sect, FGM was practiced to guarantee virginity. In the 1950s in the United States and some parts of Europe, clitoridectomy was performed to cure masturbation, nymphomania and melancholia and there is evidence that FGM has been practiced in the Philippines, amongst the Arunte people of Australia, and within the Upper Amazon (Squire, 2003, p.157). In Gambia, FGM is considered a rite of passage (Kaplan et al, 2013) while in Sierra Leone it is believed to be a religious prerequisite (Bielefeldt, 2013). In other places such as Ethiopia, Somalia and Egypt FGM is practised for the purposes of preserving a girl's virginity until marriage (Karbo, 2013). Despite all these rationales, the big question rests on the negative impact FGM has on women and their well-being.

Anthropologist, Shelley Duncan Smith (2015) refutes that women practice FGM as a means of securing a future for their children, going as far as explaining that amongst the Rendille tribe in Kenya, girls were keen on getting circumcised as they felt that this was the way to truly become women. It is important to note that the social construction of influenced by men in patriarchal communities aiming to advance their desire and aspirations can at times be conflated with aspirations and choices of women. A UNICEF report (2013) confirmed that the upholding of social norms is one of the reasons why FGM still carries on to date. The study reported that women felt pressured to perform FGM on their daughters due to several reasons, including fear of criticism, exclusion from society, stigma as well as the general fear that their daughters would be rendered unmarriageable. Diop \& Askew (2009) also states that FGM has the potential to guarantee status and acceptance within the community. In light of the above assertions, this paper seeks to explore the challenges in combatting FGM among Black Sub-Saharan African women. 


\section{Methodology}

This study aimed at exploring the challenges in combating FGM among BSSA woman in UK. Exploring perceptions and attitudes required a phenomenological approach where research participants had an opportunity to tell their lived experiences and challenges in relation to combating FGM in the UK while allowing issues of impact to them unfold. This paradigm offered the researchers an opportunity to promote a deeper understanding of the research participants' experiences as perceived by them (Charon, 2008). Guided personal narratives were collected using a conversational approach. In this way, research participants were encouraged to direct and shape the discussion in accordance with their own experiences, views and particular concerns regarding FGM (Kvale, 1996).

\section{Procedure}

\section{Identification and Recruitment of Research Participants}

Research participants were drawn from BSSA women living in the English west midlands' region. Narratives were collected from 40 research participants representing different countries in SubSahara Africa. Research participants were considered eligible if they met the following criteria

$>$ Originating from Sub-Sahara Africa.

Lived in the west midlands' region

Aged 18 years and above

\section{Ethical Considerations}

The research participants were recruited through community organisations and the researchers' social networks. All participants were provided with an information sheet and a consent form. The researchers gave further verbal information prior to the interviews and an opportunity to ask questions was offered. Only those research participants who signed up to take part in the study were contacted. Once this was done a mutually agreed date, time and place was arranged to conduct 
narrative interviews. The research participants signed the consent form before taking part in the interview. Ethical approval to conduct the study was obtained from the Research and Development Unit in the National Health Service (NHS).

\section{Narratives}

Personal narrative interviews were conducted in places where BSSA communities normally meet, which included African restaurants, faith buildings and community centres. The researcher would begin the interviews with an open question like "can you tell me how you feel about efforts and methods used in the UK to stop FGM'. An interview schedule guide with prompts was used to support this process for example prompts like "tell me more" and "how did you feel about it" "Is there anything specific you can remember" were used to elicit more detailed and clear responses where this did not occur more natural from the narrative.

It was imperative that the issues of potential bias within the research process were considered, for example the balance of power in the relationship between the research participants and the researchers (Kendall and Halliday, 2014). For example, it was important to provide a conducive atmosphere for the research participants to feel free in expressing their position with regards to the issues under consideration. Such an atmosphere would mitigate the impact of researchers in shaping responses from research participants. Considering this, the researchers kept field note diaries to note down all thoughts and feelings in order to support ongoing reflection. In addition, a distress protocol was available to support the research participants who became distressed during the interviews.

\section{Analysis}

All the narratives were recorded and transcribed verbatim. The transcripts were analysed using thematic analysis, facilitating exploration of how individuals ascribe meaning to their experiences on combating FGM in the UK (Smith et al., 1999). The analysis started at the interviewing stage, with the 
researchers keeping a record of field notes containing thoughts, feelings and emotional responses to the interview process and discussed content. The analysis process was guided by the 4 phases of the Silences framework (Serrant-Green, 2011). This helped the researchers to fully immerse themselves in the data while confirming the meaning accorded to it by the research participants including an associated group that mirrored the research participants' social group.

The narrative interviews with research participants lasted for 30-45 minutes. The transcribed data was subjected to the 4 phases of data analysis in the Silences framework (Serrant-Green, 2011).

- Phase 1: After the transcription, the data from the narrative interviews were analysed by the researchers and recurrent themes were identified as the preliminary findings.

- Phase 2: The preliminary findings from phase 1 were taken to the research participants for review in the presence of researchers noting down any comments and reflections. These reflections were used to enhance further critique in confirming or refuting the initial findings from phase 1.

- Phase 3: the social networks of the research participants did further analyses of the findings from phase 2. These participants were drawn from the BSSA communities that had not taken part in the narrative interviews. The aim was to enhance findings from phase 2 with a critical indirectly associative view.

- Phase 4: Finally, the researchers reflected on the findings from phase 3 developing emerging themes which formed the final findings from the study.

\section{Results}

Following data analysis themes supported by quotes from the research participants the research study found that stigmatisation of survivors, utilisation of Graphic images in FGM awareness, Exclusion of practising communities' gatekeepers in FGM interventions, Conflation of religion and FGM practice and emphasis on securing a conviction were challenges in combatting FGM 


\section{Stigmatisation of survivors}

The research participants felt that they were being viewed as accomplices or complicity to undergoing FGM especially by the media and other non FGM practising communities.

"Everyone keeps on talking about how bad FGM is and tend to blame the perpetrators and victims together. Honestly, no one would like to go through the FGM experience, to me the blame just makes me to feel stigmatised". A 50-year-old woman.

"The media is not helpful either, most right-wing media opposed to immigration

find news in spreading hate against the FGM practising communities without differentiating the perpetrators and survivors. Surely this brings a nasty feeling of being stigmatised and suffer a double heart ache" A 29-year-old woman.

\section{Graphic images utilisation in FGM awareness training}

The research participants felt that the use of graphic images in FGM awareness training causes trauma flash backs and disengagement among BSSA women from initiatives combatting FGM.

"I find it so difficult to cope with graphic images when they are used to raise awareness of FGM in training. It clearly traumatises survivors and sometimes makes them to experience flashbacks" A 30Year-old woman.

"I don't like FGM awareness training where graphic images are used. It traumatises survivors and gives them flashbacks. It is better to listen to a survivor than to see those graphic images" A 37-Year-old woman.

\section{Exclusion of practising communities' gatekeepers in FGM interventions}

The research participants felt that almost all of the interventions to stop FGM are focussed on women especially those from practising communities leaving men who are the gatekeepers of many FGM practising communities. 
"We all know that men regard themselves as custodians of our communities and are responsible for many things that takes place in the community including censoring what comes in and goes out of the community but they are never targeted in many FGM interventions all the obligation is left with the women" A 34 Year woman.

"I feel that men are not being condemned enough for FGM, yet they are the gatekeepers of our communities. Most of the intervention to stop FGM expect women to take initiatives, its high time men should take responsibility in interventions" A 28-Year-old woman

\section{Hood winking women into FGM through false religious pronouncements}

The research participants felt that perpetrators of FGM were falsely using religious pronouncements to entice women into FGM.

"I find it so hurting when perpetrators of FGM falsely use religion to entice women into FGM. Honestly such people need to be exposed for their hypocrisy" A 22-Year-old woman.

"I feel that so many women end up as survivors of FGM because of flattering and falsely using religion to entice them" A 32-year-old woman.

\section{Emphasis on securing a conviction}

The research participants felt that the authorities were more concerned with securing a conviction than supporting preventive programmes and FGM survivors.

"Honestly there is need to deter perpetrators of FGM however, there seems to be so much money put into investigating and following up communities to secure convictions while very little if not nothing is put in to supporting FGM preventive programmes and survivors" A 42 year old woman

"Truly I would like to see all perpetrators of FGM being convicted and jailed, however it seems that there is much emphasis on convicting perpetrators than supporting community initiatives to end FGM, are we going back to colonialism?" A 39-year-old women 


\section{Discussion}

This section of the study critically discusses and analyses the challenges in combating FGM among BSSA women from practising communities. Stigma has a long term impact on knocking confidence of the affected individuals, resulting in severe health outcomes normally associated with stress and isolation (Straetemans, Bakker \& Mitchell, 2017).The research participants reported that there was a blanket stigmatisation of the practising communities, blaming both perpetrators and FGM survivors as they were being viewed as accomplices or complicity to undergoing FGM especially by the media and other non-FGM practising communities. The perpetrators included those women and men including some gate keepers who facilitated continuation of FGM. The reported blanket stigmatisation inflicted double maltreatment on the women, leaving them vulnerable to discrimination and ridicule (Khaja, Lay \& Boys, 2010). It is therefore imperative that survivors of FGM are not viewed as complicity to the act, if the efforts to end FGM is to take shape. Professionals and other communities need to be appraised on the negative effects of stigmatising survivors of FGM in order to create a conducive atmosphere to empower them and improve their health outcomes.

The use of graphic images in health promotion takes away choice and the voice of the affected individual (Marilou, Jacob and Holmes, 2010). Utilisation of graphic images to raise awareness can also directly impact on the psychological well-being of survivors through trauma flashbacks (Biener, McCallum-Keeler and Nyman, 2000). The research participants felt that the use of graphic images in FGM awareness training causes trauma flash backs and impact on their psycho-social well-being.

It is therefore imperative to note that the actual content of raising awareness may matter more than its emotional style (Leshner, Bolls and Thomas, 2009). Fear-based awareness that solely relies on a graphic haunting message may scare the individuals but, may not necessarily lead to positive outcomes that encompasses change. "Messages which are accompanied by graphic images to induce fear have the strongest opposite effects in terms of rejection and resistance to the message." (Bradley, 2011). The key priority should be to provide awareness on how not to succumb to the health 
threat in question (FGM). This awareness is important in providing the individual with self-efficacy needed to effect necessary change and to overcome the fear engendered by the content of the awareness. Furthermore, there may be a risk that the graphic images in raising awareness end up blaming the survivor (Ahrens, 2006). Fear-based awareness must be cautious about breaking the fine line between warning about health dangers and blaming those already affected by those dangers. For example, in this study, the awareness could imply that those survivors of FGM were not cautious enough or careful enough to avoid it. This notion takes away the power and opportunities provided by survivors in health promotion packages.

Gatekeepers of communities are important in facilitating or restricting health promotion messages and acceptance of community-based interventions (Nyashanu and Serrant, 2016). In light of this assertion, it is important that gatekeepers are involved in interventions to combat health problems in communities. In this study, research participants felt that most of the interventions to stop FGM focussed on women from practising communities, leaving out men who regard themselves as gatekeepers of these communities (Ige, 2010). In many patriarchal communities' men classify themselves as the custodians of the community and responsible for censoring what comes in or goes out of it (Bhopal, 2006; Kaufman, 1987)). Although the actual practice of FGM is executed by women and is performed on women, however there is evidence that men through their power as gatekeepers and custodians of the communities, sanction it while remaining obscured in the act (Berg, \& Denison, 2013). It is therefore important that interventions or strategies to prevent FGM in practising communities should go further to include men and utilise their patriarchal power of influence as gatekeepers and perpetuators of some of these cultural practices. Furthermore, there is need to challenge certain norms and values that promote FGM in communities through the assistance of gatekeepers. This shared approach will reduce pressure and expectation on women to address the problem of FGM alone. 
Religion and its associated ideological attitudes are among the psychological variables that has been used to oppress or justify contested oppressive notions in communities (Clingingsmith, Khwaja \& Kremer, 2009). For example, in many communities, religious sacredness has been used to justify personal desires of influential people in society. Because the concept is driven through religion in many occasions falsely, which many community members believe provides no room to contest, they are more likely to accept oppressive messages and practices (Cooray and Potrafke, 2011). In this study, the research participants felt that perpetrators of FGM were falsely using religious pronouncements to entice women into FGM. The women felt that they were made to believe that they are undergoing FGM to respect and conform to the sacred religious requirements. Evidence has shown that there is no Christianity or Islamic values that support FGM yet a lot of gatekeepers and drivers of FGM have consistently linked FGM to religious conformity to make sure that resistance from women is stifled (Berg, \& Denison, 2013). It is important for professionals working with survivors of FGM to make sure that education and empowerment include exposing these falsely created connections driven by FGM perpetrators and gatekeepers.

Securing a conviction to end FGM should be drafted alongside other community friendly interventions (Maguigan, 1988). This is important in winning the support of communities and utilising the opportunities available to end FGM. The research participants felt that the authorities were more concerned with securing convictions than supporting community-based interventions to combat FGM. While it is important that perpetrators should be arrested and prosecuted, the focus should not take away other community friendly interventions which brings together professionals and communities in ending FGM. Focussing only on securing a conviction can give perpetrators an opportunity to turn communities against authorities using colonial narratives of discrimination and maltreatment even when it is not applicable (Autesserre, 2012). This can make it even harder to stop FGM when survivors of FGM are made to believe that the authorities are working against their community. It is therefore important that gender sensitive and community friendly interventions free of oppressive tendencies are utilised to unite communities and professionals against FGM, as opposed to the colonial era oppressive health interventions experienced by some of the generations in the population under study (Engel \& 
Susilo, 2014). More importantly consideration of interventions with African driven ethos of affected communities contained in philosophies like "Ubuntu meaning I am because we are" commonly used in sub-Sahara Africa to bring together communities may be effective in forging a good relationship between professionals and communities in ending FGM (Venter, 2004).

The general feeling of the research participants following discussions of the contested notions in combating FGM was that the respect of personal integrity among women was diminishing due to poor addressing of FGM issues affecting women.

\section{Implications for Practice}

There is need for a multidisciplinary approach to combatting FGM (Creighton, et al 2016). Professionals from different organisations and departments need to be educated and trained to understand the culture of practising communities and effectively help in combatting FGM. More importantly perpetrators and gate keepers in FGM practising communities need to be engaged and educated against the practise ahead of prioritising securing a conviction, as this may not impact on ending the practice. More conversations are needed with FGM survivors to understand the best ways of caring for them and tap into opportunities available to end FGM. Such engagement may be key to finding lasting solutions in ending FGM. There is need to decolonise approaches and interventions employed to end FGM in practising communities, paying attention to the concept of social justice.

\section{Limitations of the study}

This study utilised a small sample $(\mathrm{N}=40)$ compared to the number of women from BSSA communities living in the United Kingdom (UK). Future studies may need to use a larger sample incorporating different cities in the UK to enable comparisons. The study utilised a qualitative approach thereby making it difficult to generalise the findings. It is therefore hoped that future studies on the subject will consider a mixed approach paradigm to enhance generalisability and quantification of nonqualitative issues. 


\section{Concluding comments}

The discourse in FGM debate has many contested notions that have in some way diminished respect of personal integrity and empowerment of FGM survivors and women in general. There is need to consider gender sensitive interventions, which involve educating perpetrators and gatekeepers on the importance of eradicating FGM in communities. Finally, there is need to consider social justice and equality when addressing FGM issues in different communities.

\section{References}

Ahrens, C.E., (2006). Being silenced: The impact of negative social reactions on the disclosure of rape. American journal of community psychology, 38(3-4), pp.31-34.

Autesserre, S., (2012). Dangerous tales: Dominant narratives on the Congo and their unintended consequences. African Affairs, 111(443), pp.202-222.

Bentley, H., O'Hagan, O., Raff, A., \& Bhatti, I. (2016). How safe are our children. Overview of Child Protection in the UK. London: NSPCC.

Benton, L., (1999). Colonial law and cultural difference: jurisdictional politics and the formation of the colonial state. Comparative Studies in Society and History, 41(3), pp.563-588.

Berg, R. C., \& Denison, E. (2013). A tradition in transition: factors perpetuating and hindering the continuance of female genital mutilation/cutting (FGM/C) summarized in a systematic review. Health care for women international, 34(10), 837-859.

Berg, R. C., \& Underland, V. (2013). The obstetric consequences of female genital mutilation/cutting: a systematic review and meta-analysis. Obstetrics and gynecology international, 2013.

Bielefeldt, H. (2013), Report of the Special Rapporteur on freedom of religion or belief, Mission to the Republic of Sierra Leone, Human Rights Council.

Biener, L., McCallum-Keeler, G., \& Nyman, A. L. (2000). Adults' response to Massachusetts antitobacco television advertisements: impact of viewer and advertisement characteristics. Tobacco control, 9(4), 401-407.

Burrage, H. (2015) Eradicating Female Genital Mutilation- A UK Perspective, Routledge: Oxon

Bhopal, R.S. (2006) The public health agenda and minority ethnic health: a reflection on priorities. J R Soc Med 99(2):58-61.

Carby, H. (1999) White woman listen! Black feminism and the boundaries of sisterhood in Solomos, J. and Back, L. (1999), Theories of Race and Racism: A Reader, London: Routledge

Chisnell, C. and Kelly, C., (2019). Safeguarding in Social Work Practice: A Lifespan Approach. Learning Matters. 
Cooray, A. and Potrafke, N., 2011. Gender inequality in education: Political institutions or culture and religion?. European Journal of Political Economy, 27(2), pp.268-280.

Costello, S., Quinn, M., Tatchell, A., Jordan, L., \& Neophytou, K. (2015). In the best interests of the child: Preventing female genital cutting (fgc). British Journal of Social Work, 45(4), 1259-1276.

Clingingsmith, D., Khwaja, A. I., \& Kremer, M. (2009). Estimating the impact of the Hajj: religion and tolerance in Islam's global gathering. The Quarterly Journal of Economics, 124(3), 1133-1170.

Creighton, S.M., Dear, J., de Campos, C., Williams, L. and Hodes, D.,(2016). Multidisciplinary approach to the management of children with female genital mutilation (FGM) or suspected FGM: service description and case series. BMJ open, 6(2), p.e010311.

Diop, N. J., \& Askew, I. (2009). The effectiveness of a community-based education program on abandoning female genital mutilation/cutting in Senegal. Studies in family planning, 40(4), 307-318.

Dustin, M. (2010) 'Female Genital Mutilation/Cutting in the UK Challenging the Inconsistencies', European Journal of Women's Studies, 17(1):7-23

Engel, S. and Susilo, A., (2014). Shaming and sanitation in Indonesia: a return to colonial public health practices?. Development and Change, 45(1), pp.157-178.

Kaplan, A., Cham, B., Njie, L. A., Seixas, A., Blanco, S., \& Utzet, M. (2013). Female genital mutilation/cutting: the secret world of women as seen by men. Obstetrics and gynecology international, 2013.

Kaufman, M. ed., 1987. Beyond patriarchy: Essays by men on pleasure, power, and change (pp. 1-29). New York: Oxford University Press.

Khaja, K., Lay, K. and Boys, S., 2010. Female circumcision: toward an inclusive practice of care. Health care for women international, 31(8), pp.686-699.

Johnsdotter, Sara, Essén, Birgitta (2015) "Cultural change after migration: Circumcision of girls in Western migrant communities" Best Practice \& Research Clinical Obstetrics \& Gynaecology; Elsevier.

Kalev, D.H (2004) Cultural Rights or Human Rights: vol 51, Nos 5/6, Sept 2004 
Karbo, T (2013) Religion and social cohesion in Ethiopia Africa Programme of the University for Peace (UPEACE), Addis Ababa, Academic Journals. Available at:

http://www.academicjournals.org/IJPDS International Journal of Peace and Development Studies

Kemshall, H. (2010) Risk Rationalities in Contemporary Social Work Policy and Practice, The British Journal of Social Work, Volume 40, Issue 4, 1 June 2010, Pages 1247-1262

Kiragu, K. (1995), Female genital mutilation: a reproductive health concern, Population reports, Series J; Family planning programs, no. 41, pp. 1-4

Kvale, S. (2008) Interviews: Learning the Craft of Qualitative Research Interviewing. 2nd ed. Thousand Oaks, CA: Sage Publications.

Leshner, G., Bolls, P. and Thomas, E., (2009). Scare'em or disgust'em: The effects of graphic health promotion messages. Health communication, 24(5), pp.447-458.

Macfarlane, A. J. \& Dorkenoo, E. (2015). Prevalence of Female Genital Mutilation in England and Wales: National and local estimates. London: City University London in association with Equality Now.

Maguigan, H., (1998). Will Prosecutions for Female Genital Mutilation Stop the Practice in the US. Temp. Pol. \& Civ. Rts. L. Rev., 8, p.391.

Marilou G., Jacob J.D and Holmes D.(2010) "Governing Through (In)Security: A Critical Analysis of a Fear-based Public Health Campaign." Critical Public Health; 20(2):245-256.

Martinez, A., \& Phillips, K. P. (2008). Challenging ethno-cultural and sexual inequities: an intersectional feminist analysis of teachers, health partners and university student 'views on adolescent sexual and reproductive health rights. Canadian Journal of Human Sexuality, 17(3).

Millward, H. A., Kelemen, M. L., \& Mangan, A. M. (2019). Co-producing community and individual change through theatrical interventions. Organizational Aesthetics, 8(1), 34-50.

Mohanty, C.T. (1984) Under Western Eyes: Feminist Scholarship and Colonial Discourses boundary 2, Vol. 12, No. 3, On Humanism and the University I: The Discourse of Humanism, pp. 333-358

Momoh C (2003) Female genital mutilation: information for health care professionals (2nd edition), London: African Well Woman Clinic.

Momoh, C (2009) "Female Genital Mutilation" in Rai, G., Squire, C. (Ed.). (2009). The Social Context of Birth. London: Routledge.

Serrant-Green, L. (2011), "The sound of 'silence': a framework for researching sensitive issues or marginalised perspectives in health", Journal of Research in Nursing, vol. 16, no. 4, pp. 347-360. 
Shell-Duncan, B. \& Hernlund, Y. (2000) Female Circumcision in Africa: Dimensions of the Practice and Debates. In: B. Shell-Duncan \& Y. Hernlund, eds. Female "Circumcision" in Africa: Culture, Controversy, and Change. Boulder: Lynne Rienner Publishers, pp. 1-42.

Soohoo, C., (2008). Close to Home: Social Justice Activism and Human Rights. Colum. Hum. Rts. L. Rev., 40, p.7.

Strauss, A.L. \& Corbin, J.M. (1997) Grounded theory in practice, London: SAGE,

Toubia, N (1999) Caring for women with circumcision. A technical manual for healthcare providers. Rainbo,

Wadesango, N., Rembe, S., \& Chabaya, O. (2011). Violation of women's rights by harmful traditional practices. The Anthropologist, 13(2), 121-129.

Wigmore, G (2015) No Local Authority Area in England and Wales Free From FGM, No Local Authority Area in England and Wales Free From FGM

Wilson, A. M. (2013). How the methods used to eliminate foot binding in China can be employed to eradicate female genital mutilation. Journal of Gender Studies, 22(1), 17-37.

World Health Organization, UNICEF \& United Nations Population Fund. (1997). Female genital mutilation: a joint WHO/UNICEF/UNFPA statement. Geneva: World Health Organization.

World Health Organization (1997). Female genital mutilation. A joint WHO/UNICEF/UNFPA statement, Geneva, Switzerland

World Health Organization (WHO). (2008) Eliminating female genital mutilation: An interagency statement, Geneva, Switzerland: Author. Retrieved from http://www.unfpa.org/webdav/site/global/shared/documents/publications/2008/eliminating_fgm.p df

World Health Organisation, (2013) World Health Organisation. [Online] Available at: http://www.who.int/topics/female_genital_mutilation/en/

UNICEF (2013) Female Genital Mutilation/Cutting A Statistical Overview and Exploration of the Dynamics of Change, New York: UNICEF.

Shahvisi, A (2016) Why UK Doctors should be troubled by Female Genital Mutilation Legislation, Clinical Ethics, 0(0) 1-7, Sage.

Spivak, G. C. (1988). Can the subaltern speak? Basingstoke, Macmillan.

Squires C, (2003) The Social Context of Birth, Oxon: Radcliffe Medical Press Limited. 
Straetemans M, Bakker M, Mitchell E. (2017) Correlates of observing and willingness to report stigma towards HIV clients by (TB) health workers in Africa. Int J Tuberc Lung Dis.;21(11):S6-18.

Venter, E., (2004). The notion of ubuntu and communalism in African educational discourse. Studies in Philosophy and Education, 23(2-3), pp.149-160. 